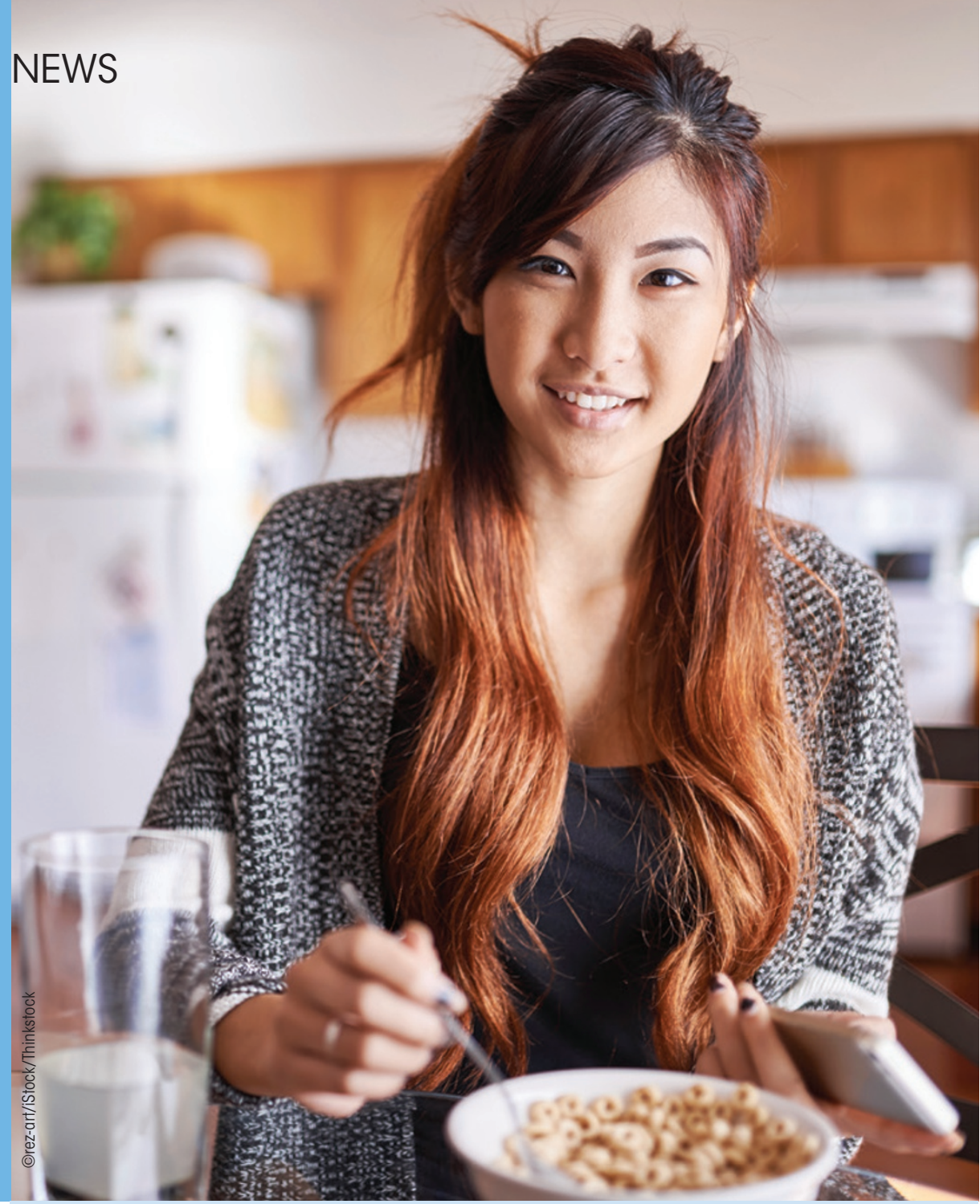

\title{
TEENS THAT SKIP BREAKFAST ARE ALMOST TWICE AS LIKELY TO HAVE BAD BREATH
}

Missing breakfast has been identified as one of the most common causes of bad breath within teenagers, according to a new report.

New research published in the International Journal of Dental Hygiene has shown evidence that teens were almost twice as likely to suffer from bad breath when they skip breakfast.

The study found that almost a fifth of the participants questioned admitted that they had missed breakfast and of these one in three (36 per cent) suffered with bad breath. This was significantly more than those who had eaten breakfast.

Interestingly, only about half of those who presented with bad breath were conscious that they were suffering from it. Chief Executive of the British Dental Health Foundation, Dr Nigel Carter OBE, believes the findings could help to have a positive effect on teenager's personal development.
'This study is very interesting as bad breath is a common problem throughout the world. Breakfast has always been widely labelled as 'the most important meal of the day' and the effect of skipping it has long been known to be detrimental to people's diets. But now there is another reason not to miss breakfast which can have a real positive impact on people's lives.

'Young people who suffer from bad breath may find that it has a significant impact on their ability to have normal social interactions as they go through one of the most defining times of their lives. This has the potential to impact their personal development and those who experience this social rejection may exhibit low self-esteem. By being aware of the causes of bad breath it gives people the ability to do something about it.'

The research also revealed that not cleaning the tongue thoroughly was another major factor in a person developing bad breath.
BLOS CHAIRMAN BRACES HIMSELF FORTHE WORLD'S TOUGHEST CYCLING CHALLENGE

This summer, Ian Hutchinson, chairman of the British Lingual Orthodontic

Society, will take on some of the world's toughest cycling terrain, during a seven day feat known as the Haute Route Alps. From 23-29 August and with fellow cyclists from around the globe, Ian will cover an impressive $781 \mathrm{~km}$ and climb upwards of 21,000 metres: the equivalent of cycling up Mount Everest - twice!

Ian has always been a keen cyclist, but found his passion often took a back seat to straightening teeth and running his own business. Now he's training every day, as the prospect of cycling from Nice to Geneva grows closer.

Ian, commented: 'Each day will be hard but the real test is perseverance seven consecutive days will prove to be a real challenge. My old orthodontic tutor Iain Hathorn used to call me a terrier as I just don't give up. I hope I don't let him down!'

Spurring Ian on is the knowledge that he'll be raising money for Guide Dogs: a UK-based charity that helps blind and partially-sighted people to enjoy the same freedom of movement as their friends and family. The breath-taking scenery of the Alps will also provide a welcome distraction - at least during the downhill sections of the course.

To sponsor Ian visit his JustGiving page at www.justgiving.com/ianhutchinson51/.



